\title{
Endostatin shows a useful value for predicting failure to recover from acute kidney injury: some confounders to consider
}

\author{
Patrick M. Honore*, Christina David, Aude Mugisha, Rachid Attou, Sebastien Redant, Andrea Gallerani and \\ David De Bels
}

Jia and colleagues have concluded that plasma endostatin shows a useful value for predicting failure to recover from acute kidney injury (AKI) [1]. They studied two populations of patients with AKI following non-cardiac major surgery, with the primary endpoint of recovery or "non-recovery" from AKI. Patients classified as "non-recovery" from AKI in fact consisted of two groups, a cohort receiving renal replacement therapy (RRT) at day 7 and another cohort without RRT [1]. We would like to make some comments. Endostatin, the C-terminal fragment of collagen XVIII, is a cytokine with a molecular weight of $20 \mathrm{kDa}$ [2]. It stands to reason that this small molecule can be easily removed by RRT as the cutoff point of filter membranes is about $35 \mathrm{kDa}$ [3]. According to the authors, patients with renal recovery showed endostatin concentrations of $62.6 \mathrm{ng} / \mathrm{ml}$, whereas patients failing to recover showed higher concentrations of $108.5 \mathrm{ng} / \mathrm{ml}$ [1]. Also, almost 20\% of the AKI population received RRT for 7 days [1]. Considering that endostatin can be removed by RRT, the endostatin values in this group of patients may fall significantly [3]. This could give the clinician the false impression that the patient will recover from AKI. Accordingly, if endostatin is used as a predictive tool in the future, falsely low endostatin values in RRT patients could lead to a premature de-escalation of care for intensive care unit (ICU) patients. There has been no

This comment refers to the article available at https://doi.org/10.1186/ s13054-018-2232-5.

* Correspondence: Patrick.Honore@CHU-Brugmann.be

ICU Department, Centre Hospitalier Universitaire Brugmann-Brugmann

University Hospital, Place Van Gehuchtenplein, 4, 1020 Brussels, Belgium investigation of the performance of endostatin in patients who receive RRT. Therefore, we believe there is a critical need for a future study with a focus on the performance of the currently known sepsis biomarkers in patients who receive RRT [4]. As noted by experts in endostatin, there is not enough evidence to date to support the use of endostatin measurements in clinical practice [5]. RRT is a good example of one of those conditions [5].

\section{Authors' response}

Endostatin is a useful biomarker to predict recovering failure from acute kidney injury

Hui-Miao Jia, Wen-Xiong Li

We appreciate the comments of Honore et al. on our article.

In this study, endostatin plasma concentration was detected immediately after acute kidney injury (AKI) diagnosis and before the renal replacement therapy (RRT) started and showed a useful value to predict the recovering from AKI failure. Early prediction aims to enable individual treatments and effective interventions that may improve clinical outcomes. Endostatin is a $28-\mathrm{kDa}$ molecule that can be removed by a high flux membrane [6]. Different filtration membranes with different bore diameters can remove different sizes of a molecule. The clearance of the biomarker is significantly dependent on the molecule size and its sieving coefficient. This article did not evaluate the performance of the biomarker in RRT; thus, we did not analyze renal recovery according to plasma endostatin concentration during RRT. Further studies may be conducted to explore this issue in the future. 


\section{Abbreviations}

AKI: Acute kidney injury; RRT: Renal replacement therapy; ICU: Intensive care unit

\section{Acknowledgements}

None.

\section{Authors' contributions}

$\mathrm{PMH}, \mathrm{SR}$, and DDB designed the paper. All authors participated in drafting the manuscript. All authors read and approved the final version.

\section{Funding}

None.

Availability of data and materials

Not applicable.

Ethics approval and consent to participate

Not applicable.

\section{Consent for publication}

Not applicable.

\section{Competing interests}

The authors declare that they have no competing interests.

Received: 30 January 2020 Accepted: 26 February 2020

Published online: 17 March 2020

\section{References}

1. Jia HM, Zheng Y, Huang LF, Xin X, Ma WL, Jiang YJ, Zheng X, Guo SY, Li WX. Derivation and validation of plasma endostatin for predicting renal recovery from acute kidney injury: a prospective validation study. Crit Care. 2018; 22(1):305. https://doi.org/10.1186/s13054-018-2232-5.

2. Rydzewska-Rosolowska A, Borawski J, Mysliwiec M. High plasma endostatin level unaffected by low-molecular weight heparin in hemodialysis patients a preliminary report. Adv Med Sci. 2009;54(2):199-202. https://doi.org/10. 2478/v10039-009-0030-7.

3. Honoré PM, De Bels D, Spapen HD. An update on membranes and cartridges for extracorporeal blood purification in sepsis and septic shock. Curr Opin Crit Care. 2018;24(6):463-8. https://doi.org/10.1097/MCC. 0000000000000542.

4. Honoré PM, Jacobs R, De Waele E, Van Gorp V, Spapen HD. Evaluating sepsis during continuous dialysis: are biomarkers still valid? Blood Purif. 2014;38(2):104-5. https://doi.org/10.1159/000363497.

5. Ruge T, Carlsson AC, Larsson A, Ärnlöv J. Endostatin: a promising biomarker in the cardiovascular continuum? Biomark Med. 2017;11(10):905-16. https://doi.org/10.2217/bmm-2017-0025 Epub 2017 Oct 4.

6. Bellini MH, Malpighi TF, Calvo FB, Miranda AR, Spencer PJ, Cichy MC, et al. Immobilized kidney 28-kDa endostatin-related (KES28 kDa) fragment promotes endothelial cell survival. Am J Nephrol. 2010;31(3):255-61.

\section{Publisher's Note}

Springer Nature remains neutral with regard to jurisdictional claims in published maps and institutional affiliations. 